\title{
Towards an Essential Biodiversity Variable for Species Interactions
}

\author{
Quentin Groom, Robert Guralnick§,।, , W. Daniel Kissling ${ }^{\#}$ \\ ‡ Botanic Garden Meise, Meise, Belgium \\ $\S$ Vertnet, Florida, United States of America \\ | University of Colorado, Boulder; University of Colorado Museum of Natural History, Boulder, United States of America \\ I University of Florida, Gainesville, United States of America \\ \# University of Amsterdam, Amsterdam, Netherlands
}

Corresponding author: Quentin Groom (quentin.groom@plantentuinmeise.be)

Received: 01 Apr 2018 | Published: 21 May 2018

Citation: Groom Q, Guralnick R, Kissling W (2018) Towards an Essential Biodiversity Variable for Species Interactions. Biodiversity Information Science and Standards 2: e25409. https://doi.org/10.3897/biss.2.25409

\section{Abstract}

Can Essential Biodiversity Variables (EBVs) be developed to monitor changes in species interactions? That was the difficult question asked at the GLOBIS-B workshop in February, 2017 in which $>50$ experts participated. EBVs can be defined as harmonized measurements that allow us to inform policy about essential changes in biodiversity. They can be seen as biological state variables from which more refined indicators may be derived. They have been presented as a means to monitor global biodiversity change and as a concept to drive the gathering, sharing, and standardisation of data on our biota (Geijzendorffer et al. 2015, Kissling et al. 2017, Pereira et al. 2013).

There are different classes of EBVs that characterize, for example, the state of species populations, species traits and ecosystem structure and function. It has also been proposed that there should be EBVs related to species interactions. However, until now there has been little progress formulating what these should be, even though species interactions are central to ecology. Species interactions cover a wide range of important processes, from mutualisms, such as pollination, to different forms of heterotrophic nutrition, such as the predator-prey relationship. Indeed, ecological interactions are critical to understand why an ecosystem is more than the sum of its parts. Nevertheless, direct observation of species interactions is often difficult and time consuming work, which makes 
it difficult to monitor them in the long-term. For this reason the workshop focused on those species interactions that are feasible to study and are most relevant to policy. To bring focus to our discussions we concentrated on pollination, predation and microbial interactions.

Taking pollination as an example, there was recognition of the importance of ecological networks and that network metrics may be a sensitive indicator of change. Potential EBVs might be the number of pairwise interactions between species or the modularity and interaction diversity of the whole network. This requires standardised data collection and reporting (e.g. standardization of measures of interaction strength or minimum data specifications for ecological networks) and sufficient data across time to regularly calculate these metrics. Other simpler surrogates for pollination might also prove useful, such as flower visitation rates or the proportion of fruit set.

Finally, there was a recognition that we do not yet have enough tools to monitor some important interactions. Many interactions, particular among microbes, can currently only be inferred from the co-occurrence of taxa. However, technology is rapidly developing and it is possible to foresee a future where even these interactions can be monitored efficiently.

Species interactions are essential to understanding ecology, but they are also difficult to monitor. Yet, delegates at the workshop left with a positive outlook that it is valuable to develop standardisation and harmonization of species interaction data to make them suitable for EBV production.

\section{Presenting author}

\section{Quentin Groom}

\section{References}

- $\quad$ Geijzendorffer I, Regan E, Pereira H, Brotons L, Brummitt N, Gavish Y, Haase P, Martin C, Mihoub J, Secades C, Schmeller D, Stoll S, Wetzel F, Walters M (2015) Bridging the gap between biodiversity data and policy reporting needs: An Essential Biodiversity Variables perspective. Journal of Applied Ecology 53 (5): 1341-1350. https:// doi.org/10.1111/1365-2664.12417

- $\quad$ Kissling WD, Ahumada J, Bowser A, Fernandez M, Fernández N, García EA, Guralnick R, Isaac NB, Kelling S, Los W, McRae L, Mihoub J, Obst M, Santamaria M, Skidmore A, Williams K, Agosti D, Amariles D, Arvanitidis C, Bastin L, Leo FD, Egloff W, Elith J, Hobern D, Martin D, Pereira H, Pesole G, Peterseil J, Saarenmaa H, Schigel D, Schmeller D, Segata N, Turak E, Uhlir P, Wee B, Hardisty A (2017) Building essential biodiversity variables (EBVs) of species distribution and abundance at a global scale. Biological Reviews 93 (1): 600-625. https://doi.org/10.1111/brv.12359

- Pereira H, Ferrier S, Walters M, Geller G, Jongman R, Scholes R, Bruford M, Brummitt N, Butchart S, Cardoso A, Coops N, Dulloo E, Faith D, Freyhof J, Gregory R, Heip C, 
Hoeft R, Hurtt G, Jetz W, Karp D, McGeoch M, Obura D, Onoda Y, Pettorelli N, Reyers B, Sayre R, Scharlemann J, Stuart S, Turak E, Walpole M, Wegmann M (2013) Essential Biodiversity Variables. Science 339 (6117): 277-278. https://doi.org/10.1126/ science.1229931 